\title{
Novel solutions supporting inter-organisational quality and information management
}

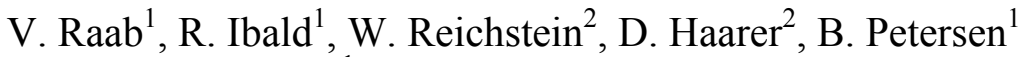 \\ \& J. Kreyenschmidt ${ }^{1}$ \\ ${ }^{I}$ Preventive Health Management Group, University of Bonn, Germany \\ ${ }^{2}$ Bayreuther Institut für Makromolekülforschung, \\ University of Bayreuth, Germany
}

\begin{abstract}
Special Time Temperature Indicators (TTI) are able to display temperature histories by colors, so that the TTIs are able to provide information of the freshness of specific products. To use TTIs in different steps of the supply chain the following requirements need to be fulfilled: Kinetic models to predict the response of the TTIs as a function of time and temperature have to be available as well as warning and action control ranges at different handover points and the ability to translate the response of the TTIs into management and product information. For an economical use of TTIs, software solutions should be available to support the participants within the supply chain with management and product information. This information results from mathematical models that use the responses of the TTIs as input and it results from knowledge what is stored in databases. The objective of this study was to develop an internet based software solution that uses a TTI kinetic model as a practical tool to use TTIs in dedicated meat supply chains. In this study the $\mathrm{OnVu}^{\mathrm{TM}}$ TTI was used and a validated model to predict the response of the TTI as a function of time and temperature and that also shows a correlation to the kinematics of the spoilage of meat. By using the model within the internet based software with an interface to the response of the TTIs, the remaining shelf life of dedicated products could be easily measured at each point within the supply chain. Within this study the implementation within a poultry supply chain was investigated.
\end{abstract}

Keywords: temperature monitoring, time-temperature-integrators, shelf life prediction, cold chain management. 


\section{Introduction}

Since quality, freshness and shelf life of meat strongly depends on temperature (Lambert et al. [1], McDonald and Sun [2], Kreyenschmidt [3], Koutsoumanis and Taoukis [4], Gospavic et al. [5], Nychas et al. [6]), the food producers must also define upper threshold temperatures that determine the validity of the estimated expiry dates of special food products. So, food producers have to estimate an expiration date under special assumptions depending on the cold chain of what the product is exposed to. This results in situations, in which the retailers declare food to be waste, because of an expired "best-use-before-date", in spite of the fact, that the food is still usable and of good quality. The reason: The exposed cold chain was much better than the assumed cold chain for what the expiration date got estimated. On the other hand, there are also customers that buy food under the assumption that it is still fresh and has a good quality, because they believe in the labelled expiration date (Labuza and Szybist [7]). But in reality it is spoiled, because of cold chains that are not as good as the food producer assumed. Both situations produce unnecessary costs. And of much bigger concern is the consumers health, food poisoning may occur due to consumption of expired or spoiled food (Fu and Labuza [8]). To avoid such scenarios it is necessary to get the information of the actual quality of the food at any given point of time, instead of the expiration dates that are only valid for predefined conditions. To reduce unnecessary costs and to be economically more efficient, a good decisions making is essential. For example FEFO (First Expires First Out) or SMAS (Safety Monitoring and Assurance System) (Giannakourou et al. [9]) could be used instead of the conventional FIFO (First In First Out) principle (Koutsoumanis et al. [10]). For such an innovative decision making, efficient temperature monitoring tools could be the basis to deliver the missing information (Olafsdottir et al. [11], Eden et al. [12]).

Today, several possibilities are on the market to monitor the temperature in each step of the supply chain. During the last years new solutions on basis of the wireless communication technology like RFID smart tags, RFIDs with temperature sensors (Jedermann et al. [13]) as well as the possibility to transfer measured temperature data in real-time, for example via GPRS (General Packet Radio Service) or Wireless Wide Area Network (WWAN) have been developed (Wang et al. [14], Ruiz-Garcia et al. [15]). Up to now most solutions cannot be used for monitoring the temperature on single item level due to much too high costs for the food industry. Therefore a suitable placement for the measuring units on pallet levels must be considered for each scenario.

Measuring units that can and would be added directly on single levels are Time Temperature Indicators (TTIs) that are very small and that do not cost more than the economical benefit what would be produced by the use of the TTIs (Taoukis and Labuza [16, 17]).

The principles of TTIs are chemical, physical or enzymatic reactions as functions of time and temperature. Its results are usually displayed by color changes of the TTI, so it is by the $\mathrm{OnVu}^{\mathrm{TM}}$ TTI (Eichen et al. [18]). If the discoloration of the label (respectively the color change) correlates with the 
spoilage of the food for different temperature conditions, the label also gives information about the actual quality of the product. In general, the label can be read out visually or technically, for example by using a spectrophotometer. The possibility to read out the color by using a spectrophotometer delivers digital information that is unambiguous and what can be used as an input for processing units, like special software.

However, to support the decision-making process of actors within supply chains, it is a necessity to translate the response of TTIs rapidly and easily into management information.

The aim of this study was the development of an internet based software solution integrating a TTI kinetic model as a practical tool to assist in applying and using TTIs in meat supply chains. For testing-reasons, the $\mathrm{OnVu}{ }^{\mathrm{TM}}$ TTI was investigated.

\section{Materials and methods}

\subsection{Description of the time temperature indicator and development of the software}

The analysed indicator was the OnVuTM label B1+081126 (Ciba Specialty Chemicals \& Freshpoint, Switzerland, patent WO/2006/048412). According to Kreyenschmidt et al. [20], the end of the products shelf life is shown by the TTIs by the time it takes until the color of the blue photochromic spot reaches a reference color. An automated UV-light charger (GLP TTI, Bizerba, Germany) was used to activate the labels when it was attached to the product. The discoloration processes of the labels were measured using a colorimeter (X-rite EyeOne i1^Basic, Gretag Macbeth, Switzerland) by measuring the Lab-values of the CIE Lab color system. Temperature loggers (iButtons, Verdict Systems BV, The Netherlands) were used to control the experiments. The square value (SV, eqn (1)) was used as a quality parameter to quantify the color changes of the TTI.

$$
S V=\sqrt{L^{2}+a^{2}+b^{2}}
$$

where SV: square Value; L: lightness; a: red and green component; b: yellow and blue component of the label.

Within previous studies the TTIs were investigated under isothermal and nonisothermal conditions within laboratory experiments and a mathematical model that describes the discoloration was developed. On basis of this model a TTI adjustment model as well as a TTI kinetic model (Kreyenschmidt et al. [20]) was developed. By using the mathematical model the TTI can be adjusted to different kind of food products by changing its initial parameters. The model was validated within a field trial in November 2009 within a poultry supply chain. The validated model is a main requirement for the use of TTIs in food supply chains and it also was the basis for the development of the software. 
The algorithm of the software was programmed by using PHP (Hypertext Preprocessor) and the use of a MySql-database, so that it is compatible with servers of commercial internet providers. The user is able to adjust the algorithm to new products and the user may deal with adjustable supply chains of up to ten different time-steps. So the user is able to simulate real or assumed timetemperature scenarios for a real or assumed spoilage behavior of foods. First validation of the basis features of the software were part of a previous TTI field trials (Raab et al. [21]).

Main features of the software are to support the monitoring, the estimation of remaining shelf life, to support storage optimization and pricing. On basis of the temperature monitoring model and the inter-organizational cold chain model of Raab et al. [19] the information requirements of the software were determined: the software should allow further data processing of the measured square values of the TTIs and it should be possible to enter the measured TTI values in any step of the food supply chain into the software which allows a comparison of the measured response of the TTIs with the predicted response. By using calculated limit ranges, the software should show whether the cold chain was in its limit or not. Therefore an easy to handle assessment of the status of the products by displaying different light fields should be programmed: green light field - cold chain was within its limits, yellow light field - cold chain was close to its limit or red light field - cold chain was not ok. Further on, the remaining shelf life under the maximum tolerable temperature should be calculated which should help the actors to take further decision regarding use, storage or selling of the products.

\subsection{Field trial scenario and validation of the model}

The chain started with the packaging of fresh chicken breast fillet in cardboard boxes (5kg, aerobic package) at a German slaughterhouse. Shelf life of the product is 164 hours (determined in previous shelf life studies (Bruckner [22])) under a maximum storage temperature of $4^{\circ} \mathrm{C}$. After palletizing the cardboard boxes were transported to a wholesaler with several unloading phases. After storage within a cold store over night, the cardboard boxes were transported to different butcher's shops close to Bonn. The chicken breast fillets arrived there approximately 24 hours after slaughtering.

At the step of the packaging in total 60 labels were activated with an initial SV0 of 57.4 (according to a shelf life of 164 hours with a maximum storage temperature of $4{ }^{\circ} \mathrm{C}$ ) and placed on top and inside of three different cardboard boxes (10 labels per side). Conventional microbiological analysis was conducted to compare the predicted shelf life on basis of the Web2.0 based software solution with the calculated shelf life on basis of the measured counts of the most important spoilage organism, Pseudomonas sp. The investigation of the samples was conducted as described by Bruckner et al. [23]. Three samples were taken out of each box at every inspection point. The spoilage level of Pseudomonas sp. for the fresh chicken breast fillet was defined at $7.5 \log 10 \mathrm{cfu} / \mathrm{g}$ according to Bruckner et al. [23]. Cardboard box 1 was stored in the cooling chamber of the butchers shop until the end of the shelf life. Cardboard boxes 2 and 3 were stored within a second cooling chamber but at cardboard box 2 a temperature abuse of 
$15^{\circ} \mathrm{C}$ for 2 hours were simulated at the step of the butchers shop (48 hours after packaging).

The responses of the TTIs, the temperature recordings of the data loggers as well as the microbiological samples were measured or checked in each step of the supply chain. The response of the TTIs were measured by using a spectrophotometer and entered directly into the software.

\section{Result and discussion}

\subsection{Web2.0 based software solution for quality-improvement by using TTIs}

Software was programmed and it is demonstrated on: http://www.ccmnetwork.com). Figure 1 shows a screenshot of the software.

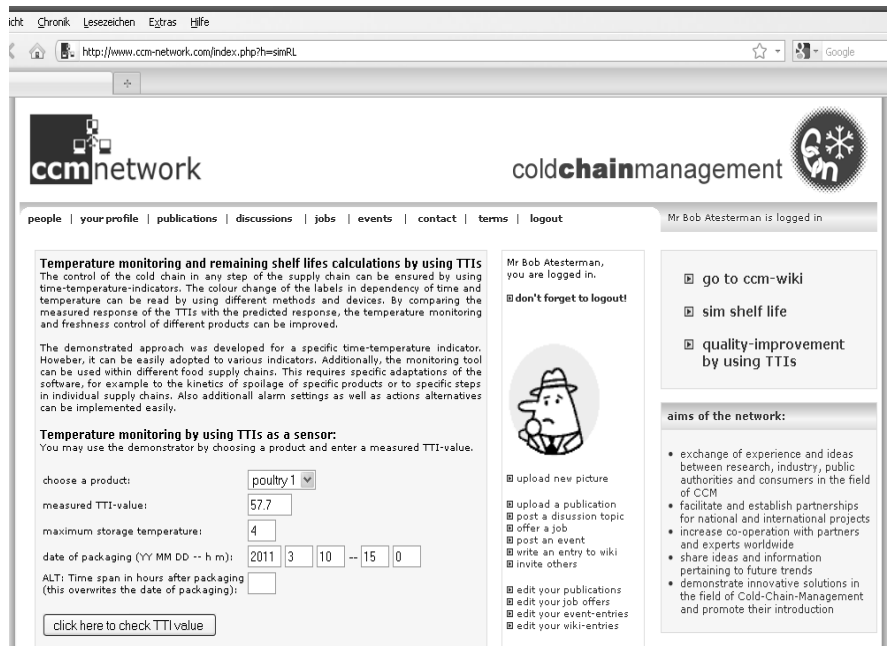

Figure 1: Screenshot of the functionality "quality-improvements by using TTIs" of the Web2.0 based software solution.

Different products can be chosen from the select box, which provides automatically that the right algorithm is chosen which was developed on basis of the laboratory investigations and validated in previous field trials. In this example the product "poultry 1" stands for the chicken breast fillet within the exemplified poultry supply chain where the above described field trials were conducted. Within the time row "maximum storage temperature" automatically a maximum storage temperature of $4^{\circ} \mathrm{C}$ is shown for this product. Furthermore any other information for stock management etc. can be easily integrated within the software. To check the response of the TTI the information regarding the date of packaging is mandatory.

The measured SV-value of the TTI has to be integrated into the row "measured TTI-value". The software calculates on basis of those values whether 
the cold chain was within its limits or not and the remaining shelf life of the product in hours.

Figure 2 shows a screenshot of the software after entering different parameters and clicking the button "CHECK TTI VALUE".

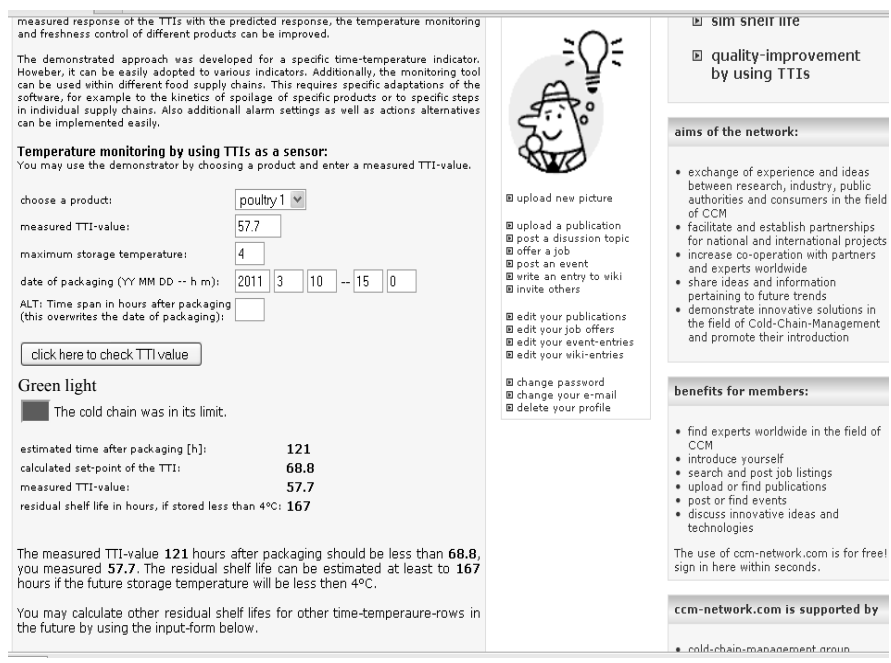

Figure 2: $\quad$ Screenshot of the functionality "quality-improvements by using TTIs" of the Web2.0 based software solution by using the option "check TTI value".

In this example the user sees that the cold chain was in its limits and that the remaining shelf life is 167 hours. If the measured TTI value would be closer to the calculated set point the user will see a yellow symbol and if the measured TTI value is much above the user will see a red sign. But in all cases the remaining shelf life in hours is calculated for further decision makings as a function of the storage temperature of the product in the future, e.g. if the measured TTI value is close to its limit within one step of the supply chain, the actor can lower the transport or/and storage temperature within the next step to prolong the shelf life. A further option of the software helps to simulate shelf lives for dedicated products depending on dynamical and adjustable timetemperature-rows. It is possible to simulate the shelf life of this product in dependency of time and temperature. Therefore specific time intervals with its specific temperatures for specific steps within the chain can be entered within the provided rows.

\subsection{Results from the field trial}

Activation of TTI-Labels took place at $2^{\circ} \mathrm{C}$ to $8^{\circ} \mathrm{C}$ in a cooling room at the company. The target value was SV 57.4. For all investigated boxes and a total of 60 TTIs an initial Square Value of $57.3 \pm 0.1$ was reached under the environmental circumstances within the slaughterhouse. According to Herranz 
and Kreyenschmidt (2009), an abbreviation of 0.2 from the calculated initial SV can be determined as an acceptable range.

The measured response of the TTIs was compared with the predicted response by using the TTI kinetic model within the software. Figure 3 gives an overview about the observed as well as the predicted limit range for each individual step for cardboard box 1 . Thereby the limit range was calculated by using the Web2.0 based software solution.

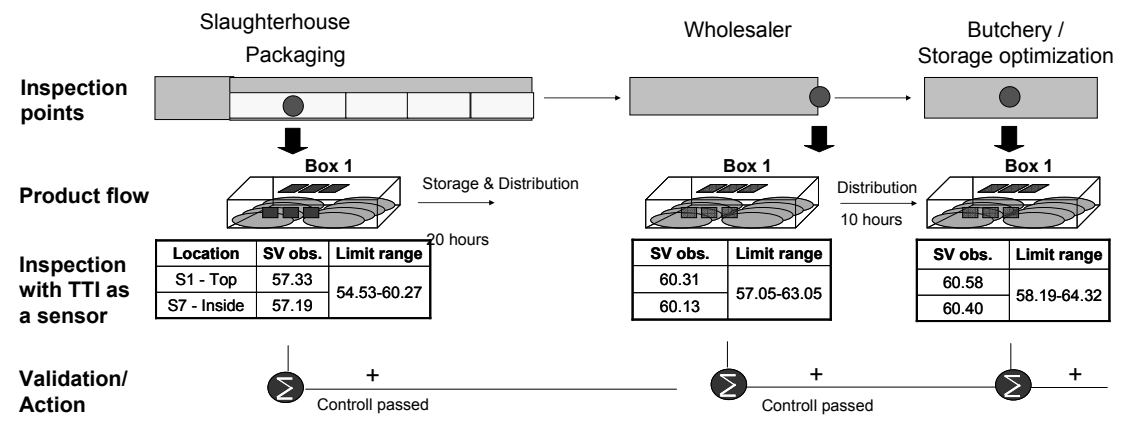

Figure 3: Comparison of the observed SV and the predicted limit range in each individual step of the supply chain for cardboard box 1 .

Box 1 was stored in the cooling chamber of the butcher's shop. The TTIs on top of the box indicated a mean shelf life of $206.6 \pm 5 \mathrm{~h}$ (8.6 days). And a mean shelf life of $223.1 \pm 5 \mathrm{~h}$ was calculated by the TTIs inside the box 1 where a mean temperature of $1.6+/-0.9^{\circ} \mathrm{C}$ was measured.

Box 2 was exposed to a temperature abuse $\left(2 \mathrm{~h}\right.$ at $\left.15^{\circ} \mathrm{C}\right)$ and stored afterwards in the cooling chamber. At a mean temperature of $2.8+/-1.5^{\circ} \mathrm{C}$ the TTIs on top of box 2 reached SV 71 after $115.8 \pm 4 \mathrm{~h}$. Box 3 also was stored in the cooling chamber. TTI-discoloration time of the TTIs on the top of box 3 indicated a mean shelf life of $156.7 \pm 5 \mathrm{~h}$ with a measured mean temperature of $3.1 \pm 1.0^{\circ} \mathrm{C}$. The TTIs on the inside of box 3 reached an SV of 71 after $163.8 \pm 5 \mathrm{~h}$. The calculated end of shelf life on basis of the measured TTI values was in a good agreement with the predicted TTI values by using the kinetic model and the Web2.0 based software. Figure 4 shows the observed and predicted response of the TTI at the top and the bottom of cardboard box 2 in comparison to the growth of Pseudomonas sp. on poultry meat within this box.

The results from the field trial validated that the TTI in combination with the software is a usable and pragmatic tool for temperature and shelf life monitoring. By entering the TTI value in real-time into the software, it could be revealed in each step, whether the cold chain was within its limit or not. As shown above, the temperature conditions within the field trial were in its range within all steps of the supply chain, except of the manipulated cold chain for cardboard box 2 .

Figures 5 and 6 show screenshots of the calculation of the remaining shelf life based on the color of the label measured after 72 hours after packaging at the top of the boxes of cardboard box 1 and 2 . 
a.

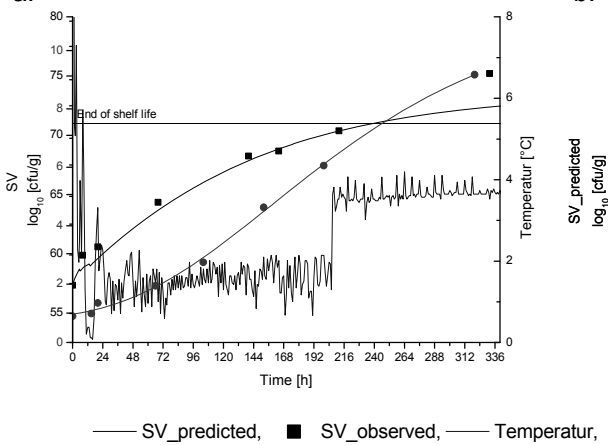

b.

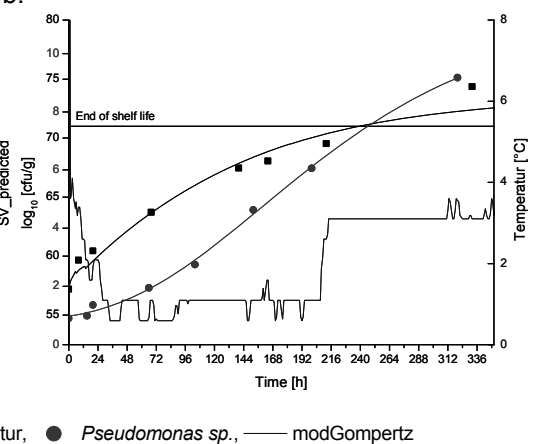

Figure 4: Example of the response of the TTIs (observed and predicted values), and growth of Pseudomonas sp. on poultry at cardboard box 1 (a. top of the box, b. inside of the box).

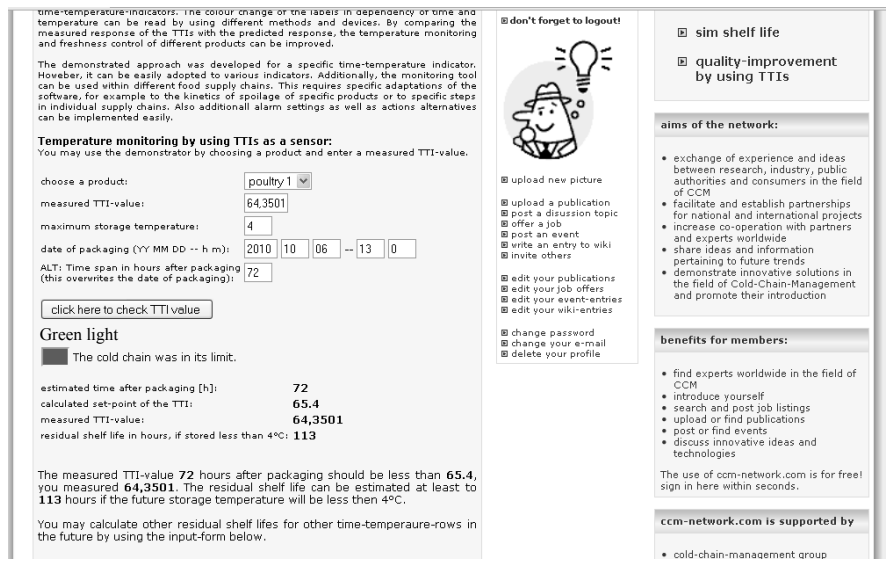

Figure 5: Screenshot of the calculation of the remaining shelf life based on the color of the label measured after 72 hours after packaging for cardboard box 1 (without simulated temperature abuse).

The screenshots show that the cold chain of cardboard box 1 was quite in its limit whereas the cold chain of cardboard box 2 was not in its limit. The results from the calculation of the software were in close agreement with the results from the scientific analysis (Figures 5 and 6). The temperature abuse within the storage period of cardboard box 2 was shown by a faster discoloration of the labels and also by a higher square value of the TTIs. By using the Web2.0 based model a shorter shelf life of the chicken breast fillet in cardboard box 2 was calculated. 


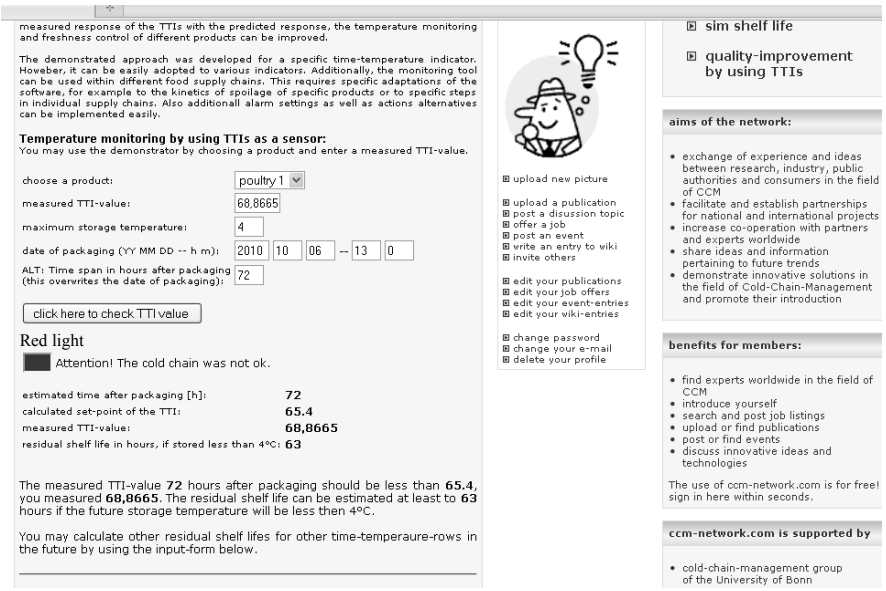

Figure 6: Screenshot of the calculation of the remaining shelf life based on the color of the label measured after 72 hours after packaging for cardboard box 2 (with simulated temperature abuse).

\section{Conclusion and prospect}

The system 'software and TTI' supports the decision making process of the actors in several ways. The actors may monitor the specific cold chain of each product and they can simulate special scenarios to optimize their cold chain management. The field test showed the applicability and usefulness of the WEB2.0 based software solution which allows an economical integration of the TTIs into temperature monitoring systems and it enhances the applications by using TTIs. A demonstration of the software is available at: http://www.ccmnetwork.com.

The described field trial was part of an extensive field trial within the European Project Chill-On (Contract no.: FP6-016333-2), conducted in October 2010. In this project novel temperature monitoring devices such as TTIs, tsensors and rf-TTIs, monitoring technologies for location, stationary and mobile management units (SMU, MMU, GIL), real-time PCR kits to monitor spoilage and pathogenic bacteria and QMRA/SLP models to predict microbial quality and safety were combined in the TRACECHILL system. The efficient implementation of TTIs in supply chains was one aim within the Chill-On project and one component of the holistic system (Chill-On [24]).

\section{Acknowledgements}

The study was partly financed by the EU-project Chill-On (FP6-016333-2). Thanks all companies and students for supporting the study. 


\section{References}

[1] Lambert, A.D., Smith, J.P. \& Dodds, K.L., Shelf life extension and microbiological safety of fresh meat - a review. Food Microbiology, 8(4), pp. 267-297, 1991.

[2] McDonald, K. \& Sun, D.W., Predictive food microbiology for the meat industry: a review. International Journal of Food Microbiology, 52(1-2), pp. 1-27, 1999.

[3] Kreyenschmidt, J.. Modellierung des Frischeverlustes von Fleisch sowie des Entfärbeprozesses von Temperatur-Zeit-Integratoren zur Festlegung von Anforderungsprofilen für die produktbegleitende Temperaturüberwachung, $\mathrm{PhD}$ thesis, Rheinische Friedrich-WilhelmsUniversität Bonn, Agrimedia Verlag, Bergen/Dumme, 2003.

[4] Koutsoumanis, K. P. \& Taoukis, P., Meat safety, refrigerated storage and transport: modeling and management. Improving the Safety of Fresh Meat, eds. J. N. Sofos, Woodhead Publishing Limited: Cambridge, pp. 503-561, 2005.

[5] Gospavic, R., Kreyenschmidt, J., Bruckner, S., Popov, V. \& Haque, N., Mathematical modelling for predicting the growth of Pseudomonas ssp. in poultry under variable temperature conditions. International Journal of Food Microbiology, 127(3), pp. 290-297, 2008.

[6] Nychas, G.-J. E., Skandamis, P. N., Tassou, C.P. \& Koutsoumanis, K. P., Meat spoilage during distribution. Meat Science, 78(1-2), pp. 77-89, 2008.

[7] Labuza, T. P. \& Szybist, L. M., Open Dating of Foods, Food \& Nutrition Press, Inc.: Trumbull, Connecticut, 2008.

[8] $\mathrm{Fu}, \mathrm{B}$. \& Labuza T.P., Considerations for the Application of Time-Temperature Integrators in Food Distribution, Journal of Food Distribution Research, 23(1), pp. 9-18, 1992.

[9] Giannakourou, M.C., Koutsoumanis, K., Nychas, G.J.E. \& Taoukis, P.S., Field evaluation of the application of time temperature integrators for monitoring fish quality in the chill chain. International Journal of Food Microbiology, 102(3), pp. 323-336, 2005.

[10] Koutsoumanis, K. P.; Taoukis, P.; Nychas, G.-J E., Development of a Safety Monitoring and Assurance System for chilled food products. International Journal of Food Microbiology, 100, pp. 253-260, 2006.

[11] Ólafsdóttir, G., S. Bogason, C. Colmer, M. Eden, T. Hafliðason \& Kück, M., Improved efficiency and real time temperature monitoring in the food supply chain. $1^{\text {st }}$ IIR International Cold Chain and Sustainability Conferences. Cambridge, 2010.

[12] Eden, M., Raab, V., Kreyenschmidt, J., Hafliðason, T., Ólafsdóttir, G. \& Bogason, S.G., Continuous temperature monitoring along the chilled food supply chain. Food chain integrity: a holistic approach to food traceability, safety, quality and authenticity, eds. J. Hoorfar, K. Jordan, F. Butler \& R. Prugger, Woodhead Publishing: Cambridge, pp. 115-129, 2011. 
[13] Jedermann, R., Ruiz-Garcia, L. \& Lang, W., Spatial temperature profiling by semi-passive RFID loggers for perishable food transportation. Computers and Electronics in Agriculture, 65, pp. 145-154, 2009.

[14] Wang, N., Zhang, N. \& Wang, M. Review. Wireless sensors in agriculture and food industry -- Recent development and future perspective. Computers and Electronics in Agriculture, 50(1): 1-14, 2006.

[15] Ruiz-Garcia, L., Steinberger, G. \& Rothmund, M., A model and prototype implementation for tracking and tracing agricultural batch products along the food chain, Food Control, 21(2), pp. 112-121, 2010.

[16] Taoukis, P.S. \& Labuza, T.P., Applicability of time-temperature indicators as shelf life monitors of food products. Journal of Food Science, 54(4), pp. 783-788, 1989.

[17] Taoukis, P.S. \& Labuza, T.P., Reliability of time-temperature indicators as food quality monitors under non-isothermal conditions. Journal of Food Science, 54(4), pp. 789-792, 1989.

[18] Eichen, Y., Haarer, D., Feuerstack, M., Jannasch, U., Bücken, W., Uber, M., Nisbet, T., Reichert, H., Feiler, L. \& Fuchs, A., What it takes to make it work: the $\mathrm{OnVu}^{\mathrm{TM}}$ TTI. Proc. of the $3^{\text {rd }}$ Int. Workshop Cold-ChainManagement, $2^{\text {nd }}-3^{\text {rd }}$ of June 2008, eds. J. Kreyenschmidt, Bonn, 2008.

[19] Raab, V.; Bruckner, S.; Beierle, E.; Kampmann, Y. \& Petersen, B., Generic model for the prediction of remaining shelf life in support of cold chain management in pork and poultry supply chains. Journal on Chain and Network Science, 8(1), pp. 59-73, 2008.

[20] Kreyenschmidt, J., Christiansen, H., Huebner, A., Raab, V. \& Petersen, B., A novel photochromic time-temperature indicator to support cold chain management. International Journal of Food Science \& Technology, 45(2), pp. 208-215, 2010.

[21] Raab, V., Ibald, R., Albrecht, A., Petersen, B. \& Kreyenschmidt, J., WEB2.0 based Software Solution to support a practical implementation of Time Temperature Indicators. Proc. of the 4th Int. Workshop Cold Chain Management, eds. J. Kreyenschmidt, Bonn, pp. 57-58, 2010.

[22] Bruckner, S., Predictive shelf life model: A new approach for the improvement of quality management in meat chains. $\mathrm{PhD}$ thesis, Rheinische Friedrich-Wilhelms-Universität Bonn, Südwestdeutscher Verlag für Hochschulschriften, Saarbrücken, 2010.

[23] Bruckner, S.; Raab, V. \& Kreyenschmidt, J., Concept for the implementation of a generic model for remaining shelf life prediction in meat supply chains. $6^{\text {th }}$ Int. Conference Predictive Modeling in Foods Meeting Abstracts and Information Booklet, 08 $-12^{\text {th }}$ September 2009, Washington DC, USA. [published on CD], 2009.

[24] Chill-On, Chill-On Field Trials Summary Report, Online. www.chill-on.com/final-report.html, 2011. 